\title{
Design and Experiment Study of Ultrasonic Longitudinal-Torsional Compound Consolidation Vibration System for Metal Foil
}

\author{
Xiangqiang Zhong, ${ }^{1,2}$ Benxue Zhang, ${ }^{2}$ Weiqing Huang $\mathbb{D}^{3}{ }^{3}$ Zhimin Di, $^{2}$ and Huajie Fang ${ }^{2}$ \\ ${ }^{1}$ State Key Laboratory of Mechanics and Control of Mechanical Structures, Nanjing University of Aeronautics and Astronautics, \\ Nanjing 210016, China \\ ${ }^{2}$ School of Mechanical and Automotive Engineering, Anhui Polytechnic University, Wuhu 241000, China \\ ${ }^{3}$ School of Mechanical and Electrical Engineering, Guangzhou University, Guangzhou 510006, China
}

Correspondence should be addressed to Weiqing Huang; 3376385213@qq.com

Received 7 May 2020; Revised 26 June 2020; Accepted 2 July 2020; Published 31 July 2020

Academic Editor: Giuseppe Petrone

Copyright (c) 2020 Xiangqiang Zhong et al. This is an open access article distributed under the Creative Commons Attribution License, which permits unrestricted use, distribution, and reproduction in any medium, provided the original work is properly cited.

\begin{abstract}
In order to realize the connection for metal foil, a longitudinal-torsional compound consolidation vibration system is proposed, and relative experiments are carried out. Firstly, the structure of longitudinal-torsional compound consolidation vibration system was designed, detailed structural design of the compound piezoelectric transducer and the compound horn in the vibration system was carried out, and torsional vibration analysis of the compound horn with spiral grooves was carried out based on mechanical principle. Secondly, modal calculation and harmonic response analysis of longitudinal-torsional compound consolidation vibration system were carried out, and corresponding vibration mode and harmonic frequency were obtained. The effect of structural parameters for the compound horn on the frequency of the consolidation vibration system was analysed, and structural parameters of the compound horn were optimized. Finally, the prototype was made, and the experimental platform was built to test the amplitude. When the frequency is near $20000 \mathrm{~Hz}$, the resonance is achieved in three directions at the same time, and the resonance frequency is $19800 \mathrm{~Hz}$. Through the frequency-scanning test, the maximum longitudinal amplitude of the consolidation vibration system is $16 \mu \mathrm{m}$, and the maximum torsional amplitudes of $X$ and $Y$ are $7.9 \mu \mathrm{m}$ and $8.1 \mu \mathrm{m}$. The longitudinal-torsional compound consolidation vibration system can realize the connection of the same and different metal foils and has broad application prospects.
\end{abstract}

\section{Introduction}

Ultrasonic additive manufacturing for metal foil has the advantages of low forming temperature, small deformation, fast speed, and no pollution. A variety of metal foils and embed low melting point materials or electronic devices such as sensors, alloy fibres, and other temperature-sensitive materials can be connected and are widely used in the manufacturing of intelligent structures and materials [1-4]. To connect metal foils under certain pressure, it is usually achieved under one-dimensional longitudinal vibration mode by the traditional additive manufacturing equipment. The consolidation mechanism is clear but accompanied with some shortcomings; it cannot apply to thick and hard metal foil such as titanium alloy and stainless steel. Therefore, the research on two-dimensional compound ultrasonic consolidation vibration system for metal foil becomes a hot spot.

A system for use in ultrasonic additive manufacturing processes was invented by Norfolk et al. [5], comprising the milling machine or the like and a welded assembly. Graff et al. [6] invented an ultrasonic welding apparatus that included a full-wave sonotrode that further included a first horn, a first nodal region, a welding surface, a second nodal region, and a second horn.

Tsujino et al. [7-10] studied transverse and torsional complex vibration systems for ultrasonic seam welding of 
metal plate specimens, using a $27 \mathrm{kHz}$ welding tip with complex vibration disk vibrating in transverse and torsional vibration modes. The complex vibration system can continuously weld multiple parts of metal plate specimens such as heat sinks with a large number of fins.

An ultrasonic longitudinal-torsional vibration source which could be controlled was developed by Asami et al. [11]. It consisted of two transducers, a longitudinal transducer and a torsional transducer, attached to the ends of a uniform rod with a length of one wavelength of the propagating vibration.

Al-Budairi et al. [12, 13] studied combining longitudinal and torsional vibration responses at the output face of a Langevin transducer. A mode degeneration method was adopted that converted the longitudinal response excited by the axially poled piezoceramic discs in the transducer into combined longitudinal-torsional vibration in the transducer front mass using geometric modifications of the wave path.

Ultrasonic additive manufacturing system for longitudinal vibration and the design approach for longitudinaltorsional ultrasonic transducers have been studied in the above research work, but there are few studies on longitudinal-torsional compound consolidation vibration system for metal foil.

In this paper, longitudinal-torsional compound consolidation vibration system for metal foil was designed, the structure and working principle were analysed, and the optimization design of the consolidation vibration system was carried out. The longitudinal and torsional amplitudes were tested. The experiment proved the feasibility of the longitudinal-torsional compound consolidation vibration system.

\section{Structural Design of Longitudinal-Torsional Compound Consolidation Vibration System for Metal Foil}

In order to better explore the effect of ultrasonic vibration mode on the consolidation for metal foil, based on UG NX, a hybrid top-down and bottom-up assembly method was adopted to establish the overall structure, as shown in Figure 1. The system mainly includes a piezoelectric transducer, the compound horn with spiral grooves, and consolidation sonotrode [14-16].

The working principle of the consolidation vibration system is as follows. Flange 7 is used for positioning the whole consolidation vibration system; pretightening bolt 5 makes piezoelectric ceramic 6 fasten between the front cover plate and rear cover plate. When an ultrasonic signal is input, longitudinal vibration is generated by the piezoelectric transducer and then is transformed into longitudinal-torsional compound vibration through spiral grooves. Under a static pressure applied to consolidation sonotrode 8, friction heat is generated between metal foils, and then plastic deformation occurs, and the consolidation for metal foil is achieved.

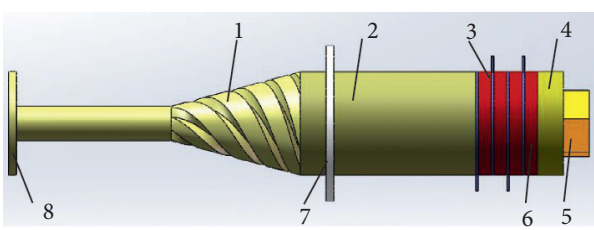

Figure 1: The overall structure of longitudinal-torsional compound consolidation vibration system. 1: spiral groove; 2: front cover plate; 3: electrode slices; 4: rear cover plate; 5: fastening bolt; 6: piezoelectric ceramics; 7: flange; 8: consolidation sonotrode.

2.1. Design of the Compound Piezoelectric Transducer. The piezoelectric transducer is the key component of longitudinal-torsional compound consolidation vibration system. Its vibration mode belongs to longitudinal vibration. It uses the reverse piezoelectric effect of piezoelectric ceramics to generate the vibration.

2.1.1. Equivalent Circuit of the Piezoelectric Transducer. The equivalent circuit of the piezoelectric transducer mainly includes the front cover plate, piezoelectric ceramics and rear cover plate. As shown in Figure 2, $Z_{01}, Z_{a 2}$, and $Z_{a 3}$ are the impedance of the rear cover plate. $Z_{01}$ and $Z_{02}$ are the impedance of piezoelectric ceramics. $Z_{b 1}, Z_{b 2}$, and $Z_{b 3}$ are the impedance of the front cover plate. $Z_{b}$ is the load impedance of the rear cover plate. $Z_{f}$ is the load impedance of the front cover plate. $I$ is the circuit current. $V$ is the circuit voltage. $C_{0}$ is the circuit capacitance. When the transducer is designed and calculated, the load impedance of $Z_{b}$ and $Z_{f}$ can be removed.

\subsubsection{Frequency Equation of the Piezoelectric Transducer.} The frequency equation of the piezoelectric transducer is the key to the structural design of the transducer. The frequency equation is related to the structure, shape, and material characteristics of the transducer components. The nodal plane selection of the transducer affects the structural dimension, which is the basis of the transducer design. The piezoelectric transducer node designed in this paper is at the front cover plate, as shown in Figure 3. $l_{1}, l_{2}$, $l_{3}$, and $l_{4}$ are different position sizes of the transducer, $l_{4}=\left(\lambda_{c} / 4\right)$. The frequency equation of the transducer node at the front cover plate is shown in the following equation:

$$
\begin{aligned}
& \frac{Z_{3}}{Z_{2}} \tan k_{2} l_{2} \tan k_{3} l_{3}+\frac{Z_{3}}{Z_{1}} \tan k_{1} l_{1} \tan k_{3} l_{3} \\
& +\frac{Z_{2}}{Z_{1}} \tan k_{1} l_{1} \tan k_{2} l_{2}=1,
\end{aligned}
$$

where $k_{1}=24.7 \mathrm{~m}^{-1}, k_{2}=40.5 \mathrm{~m}^{-1}$, and $k_{3}=23.9 \mathrm{~m}^{-1}$.

\subsubsection{Size Calculation of the Piezoelectric Transducer.} The material characteristic parameters for different components of the transducer are shown in Table 1.

Using the frequency equation (1) and the data in Table 1, the dimensions of different structures of the transducer can be calculated. 


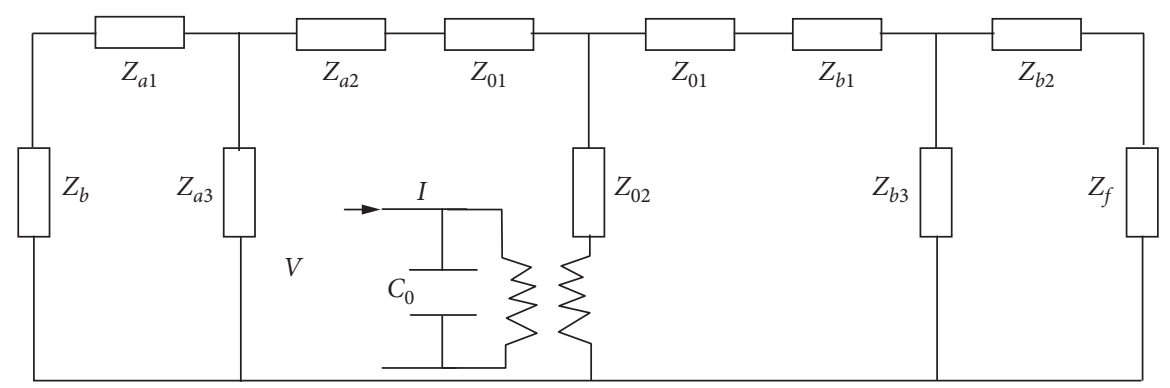

FIGURE 2: The equivalent circuit of the transducer.

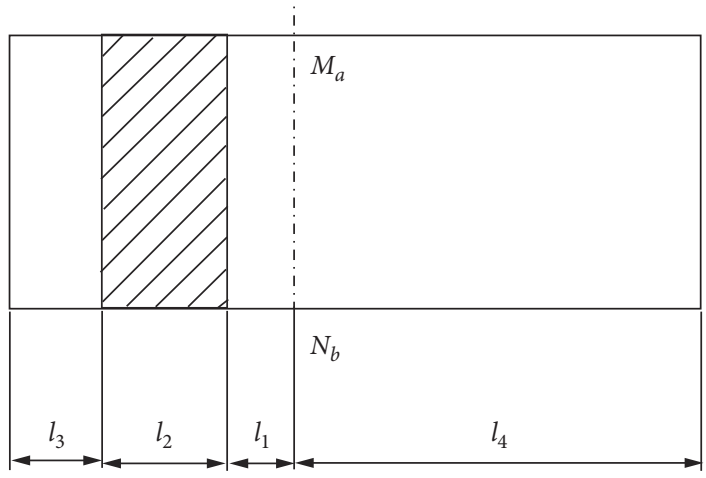

Figure 3: Nodal plane at the front cover plate.

TABLe 1: Material parameters of ultrasonic transducer.

\begin{tabular}{lcccc}
\hline Material & $\begin{array}{c}\text { Density } \rho 10^{3} \\
\left(\mathrm{~kg} / \mathrm{m}^{3}\right)\end{array}$ & $\begin{array}{c}\text { Elastic modulus } E 10^{11} \\
\left(\mathrm{~N} / \mathrm{m}^{2}\right)\end{array}$ & $\begin{array}{c}\text { Poisson's ratio } \\
\mu\end{array}$ & $\begin{array}{c}\text { Longitudinal wave velocity C } \\
\mathrm{m} / \mathrm{s}\end{array}$ \\
\hline Piezoelectric ceramic PZT-8 & 7.5 & 0.59 & 0.35 & 3100 \\
Electrode slices (copper strip) & 8.9 & 1.23 & 0.35 & 3718 \\
Front cover plate (aluminum alloy) & 2.7 & 0.70 & 0.34 & 5090 \\
Rear cover plate (45\# steel) & 7.8 & 2.16 & 0.28 & 5262 \\
Prestressed screw (40 Cr) & 7.75 & 2.15 & 0.29 & 5267 \\
Horn (45\# steel) & 7.8 & 2.16 & 0.28 & 5262 \\
Sonotrode (45\# steel) & 7.8 & 2.16 & 0.28 & 5262 \\
\hline
\end{tabular}

Piezoelectric ceramic is PZT-8, the radius is $R_{1}=20 \mathrm{~mm}$, the thickness is $5 \mathrm{~mm}$, four pieces are taken, the radius of electrode slices is the same as that of piezoelectric ceramic, the radius is also $R_{2}=20 \mathrm{~mm}$, the thickness is $1 \mathrm{~mm}$, and $l_{2}=5 \times 4+1 \times 4=24 \mathrm{~mm}$.

The rear cover plate is $45 \#$ steel, the radius is $R_{3}=20 \mathrm{~mm}$, and the length is $10 \mathrm{~mm}$. $l_{4}=\left(\lambda_{c} / 4\right)=$ $(c / 4 f)=(5262 / 4 / 20)=65.8 \mathrm{~mm}$, the value is rounded to $66 \mathrm{~mm}$.

Taking $l_{2}, l_{3}$, and $l_{4}$ and the data in Table 1 into equation (1), $l_{1}=4.5 \mathrm{~mm}$ is calculated. Therefore, the length of front cover plate of the transducer is $l_{1}+l_{4}=70.5 \mathrm{~mm}$ and the radius is $R_{4}=20 \mathrm{~mm}$.

2.2. Design of Longitudinal-Torsional Compound Horn. In the longitudinal-torsional compound piezoelectric consolidation vibration system, the horn is the key component. The horn amplifies the vibration of the transducer and transmits it, and the consolidation requirement for metal foil is met [17-19].

2.2.1. Frequency Equation of Conical Compound Horn. In order to meet the requirements of the consolidation vibration system, the design of stepped conical compound horn is adopted, which can not only ensure the amplitude magnification but also ensure the stability of vibration transmission by giving the need for big amplitude and high stability of longitudinal-torsional compound piezoelectric vibration system for metal foil. The structure and boundary conditions of stepped conical compound horn are shown in Figure 4.

The frequency equation of the compound horn is shown in the following equation: 


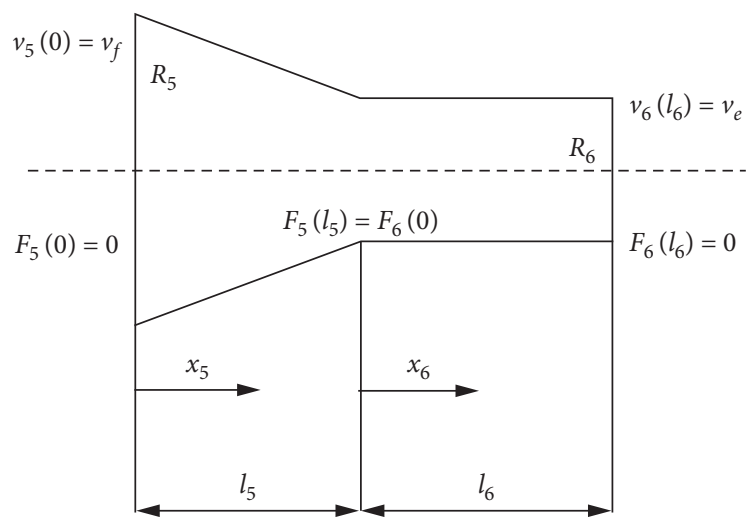

FIgUre 4: Stepped conical compound horn.

$$
\tan k_{6} l_{6}=\frac{a^{2} k_{5} l_{5}-\left[a^{2}+b\left(k_{5} l_{5}\right)^{2}\right] \tan k_{5} l_{5}}{k_{5} l_{5}\left(b k_{5} l_{5}-a \tan k_{5} l_{5}\right)}
$$

where, $a=\left(\left(R_{5}-R_{6}\right) / R_{6}\right), \quad b=\left(R_{5} / R_{6}\right), \quad$ and $k_{5}=k_{6}=$ $23.9 \mathrm{~m}^{-1}$.

The amplitude magnification of the compound horn is shown in the following equation:

$$
M_{p}=\frac{R_{5}}{R_{6}}\left(\cos k_{5} l_{5}-\frac{1}{k_{5} l_{5}} \frac{R_{5}-R_{6}}{R_{6}} \sin k_{5} l_{5}\right) \frac{1}{\cos k_{5} l_{5}} .
$$

In order to match with the output end of the transducer, the radius of the big end conical part is $R_{5}=20 \mathrm{~mm}$, the length is $l_{5}=50 \mathrm{~mm}$, and the radius of the small end cylinder is $R_{6}=6.66 \mathrm{~mm}$.

Taking $a=2, b=3$, and $k_{5} l_{5}=1.195$ into (2) and (3), $l_{6}=60 \mathrm{~mm}$ and $M_{p}=6.48$ are calculated.

2.2.2. Torsional Vibration Analysis of the Compound Horn with Spiral Grooves Based on Mechanical Principle. At present, there are two ways to generate longitudinal-torsional vibration in the ultrasonic vibration system. One is to use the axial and tangential polarization of piezoelectric ceramics, which is easy to make the polarization effect of piezoelectric ceramics poor. The other is to use the modal conversion method to transform the longitudinal vibration into the longitudinal-torsional compound vibration through a structure, which is relatively simple. The compound horn with spiral grooves is shown in Figure 5. The inclination angle of spiral grooves is $\beta . r_{1}$ is the small end radius of the compound horn, and $r_{2}$ is the big end radius of the compound horn.

The spiral groove divides the vibration force $F$ into the axial force $F_{1}$ and the tangential force $F_{2}$, in which the tangential force $F_{2}$ causes the torsional vibration of the compound horn and the axial force $F_{1}$ causes the longitudinal vibration of the compound horn. The relationship between them is shown in the following equation:

$$
\left\{\begin{array}{l}
F_{1}=F \cos \beta \\
F_{2}=F \sin \beta .
\end{array}\right.
$$

The torque $M_{T}$ generated by torsional vibration is shown in the following equation:

$$
M_{T}=\int_{S} r f_{T} \mathrm{~d} S
$$

where $r$ is the radius of the spiral groove at any section and $f_{T}=(F \sin \beta / S)$ is the unit area tangential force of the spiral groove.

The approximate calculation of the cross-sectional area of the spiral groove at any position is shown in the following equation:

$$
S=\pi r^{2}-2 h \sin \beta\left(r_{1}<r \leq r_{2}\right),
$$

where $h$ is the depth of the spiral groove.

Equation (7) can be obtained from the following equation:

$$
d S=2 \pi r d r
$$

The following equation can be obtained from (5)-(7):

$$
M_{T}=2 F \sin \beta\left(r_{2}-r_{1}-\sqrt{(2 h \sin \beta / \pi)} \operatorname{arctanh}\left(\frac{r_{2}}{\sqrt{(2 h \sin \beta / \pi)}}\right)+\sqrt{(2 h \sin \beta / \pi)} \operatorname{arctanh}\left(\frac{r_{1}}{\sqrt{(2 h \sin \beta / \pi)}}\right)\right) .
$$

From the moment expression, the transducer can generate both the longitudinal vibration and the torsional vibration by means of the effect of the spiral groove, which can realize the longitudinal-torsional compound vibration.
In order to realize the consolidation for metal foil, a consolidation disk should be installed at the front end of the compound horn with spiral grooves. 


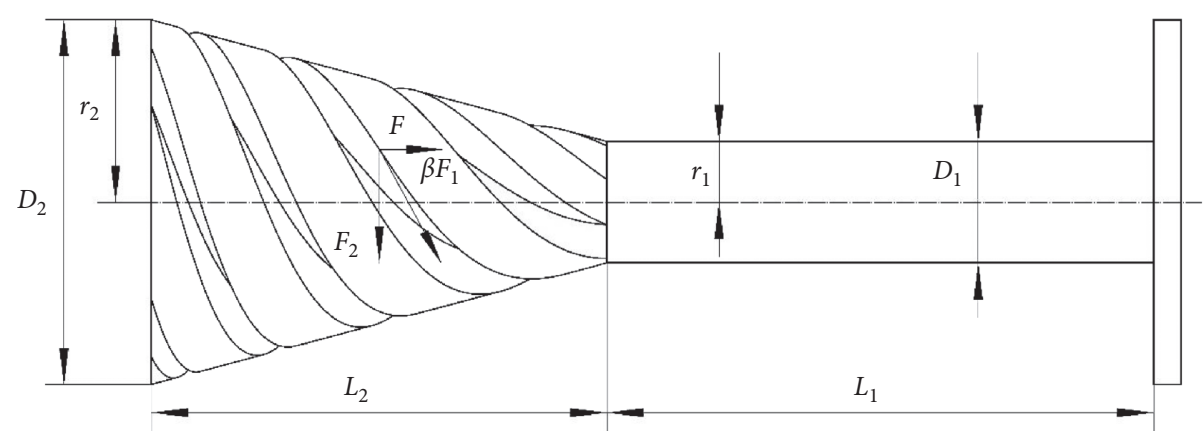

FIgURE 5: Spiral groove structure.

\section{Optimization Design of Longitudinal- Torsional Compound Consolidation Vibration System for Metal Foil}

In order to realize the consolidation for metal foil, the calculation and analysis of the longitudinal-torsional compound consolidation vibration system are carried out, then the harmonic response analysis is carried out, the effect of structural parameters of the compound horn on the frequency of the consolidation vibration system is studied, and structural parameters of the compound horn are optimized [20-24].

\subsection{Modal Analysis of Longitudinal-Torsional Compound} Consolidation Vibration System for Metal Foil. Through modal analysis, the vibration mode and frequency of the structure can be observed intuitively, and then the correct modal order can be selected to lay the foundation for the structural optimization.

3.1.1. Modal Analysis of the Transducer. Modal analysis flow of the transducer is as follows. Firstly, NX and ANSYS are connected bidirectionally. Secondly, material properties of each component are defined for the transducer model, the contact type is defined, the mesh is generated, the number of modes is set to 6 , and the frequency range is set between $15000 \mathrm{~Hz}$ and $21000 \mathrm{~Hz}$. The transducer has no external load and belongs to free modal analysis. The simulation results show that the transducer belongs to the longitudinal vibration, the maximum amplitude is at the front of the front cover plate, the node position is on the left side of the front cover plate, the vibration frequency is $19801 \mathrm{~Hz}$, the difference from the design frequency of $20 \mathrm{kHz}$ is $199 \mathrm{~Hz}$, and the error is $1 \%$ and less than $5 \%$, which meets the engineering requirements.

3.1.2. Modal Analysis of the Compound Horn. According to different spiral grooves of the compound horn, the modal analysis is carried out based on ANSYS, and the effect of the number of spiral grooves on modal frequency of the compound horn is shown in Figure 6.

It can be seen from Figure 6 that the vibration frequency of the compound horn decreases with the increase of the number of spiral grooves. When the number of spiral grooves is 6 , the vibration frequency of the compound horn is the closest to the design frequency of $20 \mathrm{kHz}$. As the number of spiral grooves increases, processing becomes more difficult, the strength and rigidity of the compound horn will decrease, and the stress concentration will appear, the damage is easy to occur. According to the simulation results, the number of spiral grooves can be 4 , the vibration frequency of the compound horn is $21037 \mathrm{~Hz}$, which is quite different from the theoretical design frequency, and the structural parameters need to be optimized further.

\subsubsection{Modal Analysis of Longitudinal-Torsional Compound} Vibration System. According to the simulation results, the vibration frequency of the longitudinal-torsional compound vibration system without flange is $20576 \mathrm{~Hz}$, the difference from theoretical design frequency of $20 \mathrm{kHz}$ is $576 \mathrm{~Hz}$, and the error is $2.88 \%$ and less than $5 \%$, which meets the design requirements. The vibration frequency with flange is $20355 \mathrm{~Hz}$, the solution result is shown in Figure 7, the difference from theoretical design frequency of $20 \mathrm{kHz}$ is $355 \mathrm{~Hz}$, and the error is $1.78 \%$ and less than $5 \%$, which meets the design requirements. The purpose of adding flange is to facilitate the positioning and clamping of longitudinaltorsional compound vibration system. Through the finite element modal calculation, all of them are within the allowable error range and meet the engineering requirements.

3.2. Harmonic Response Analysis of Longitudinal-Torsional Compound Consolidation Vibration System for Metal Foil. Harmonic response analysis belongs to frequency response analysis, also known as frequency-scanning analysis, which is the amplitude response of the system under the frequency excitation.

Before harmonic response analysis of longitudinal-torsional compound consolidation vibration system, modal analysis is carried out firstly, the longitudinal-torsional frequency of compound consolidation vibration system is $20335 \mathrm{~Hz}$, and the frequency response range can be set to $19000-21000 \mathrm{~Hz}$. A point on the sonotrode is selected as the harmonic response point. After the harmonic response calculation, the amplitudes of $X, Y$, and $Z$ at the end of longitudinal-torsional compound consolidation vibration system are $9.31 \mu \mathrm{m}, 9.22 \mu \mathrm{m}$, and $18.8 \mu \mathrm{m}$. The simulated longitudinal amplitude of the transducer is $3 \mu \mathrm{m}$, the 


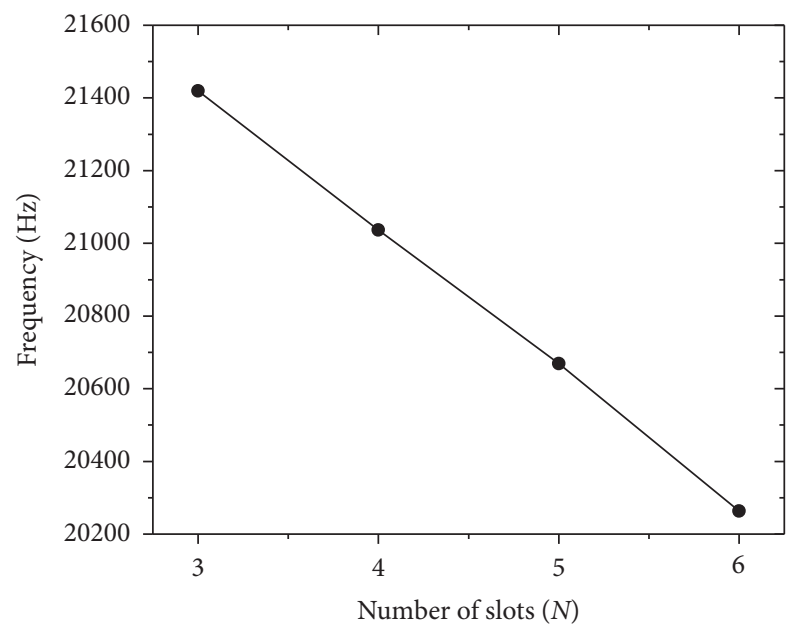

FIGURE 6: The effect of the number of spiral grooves on frequency of the compound horn.

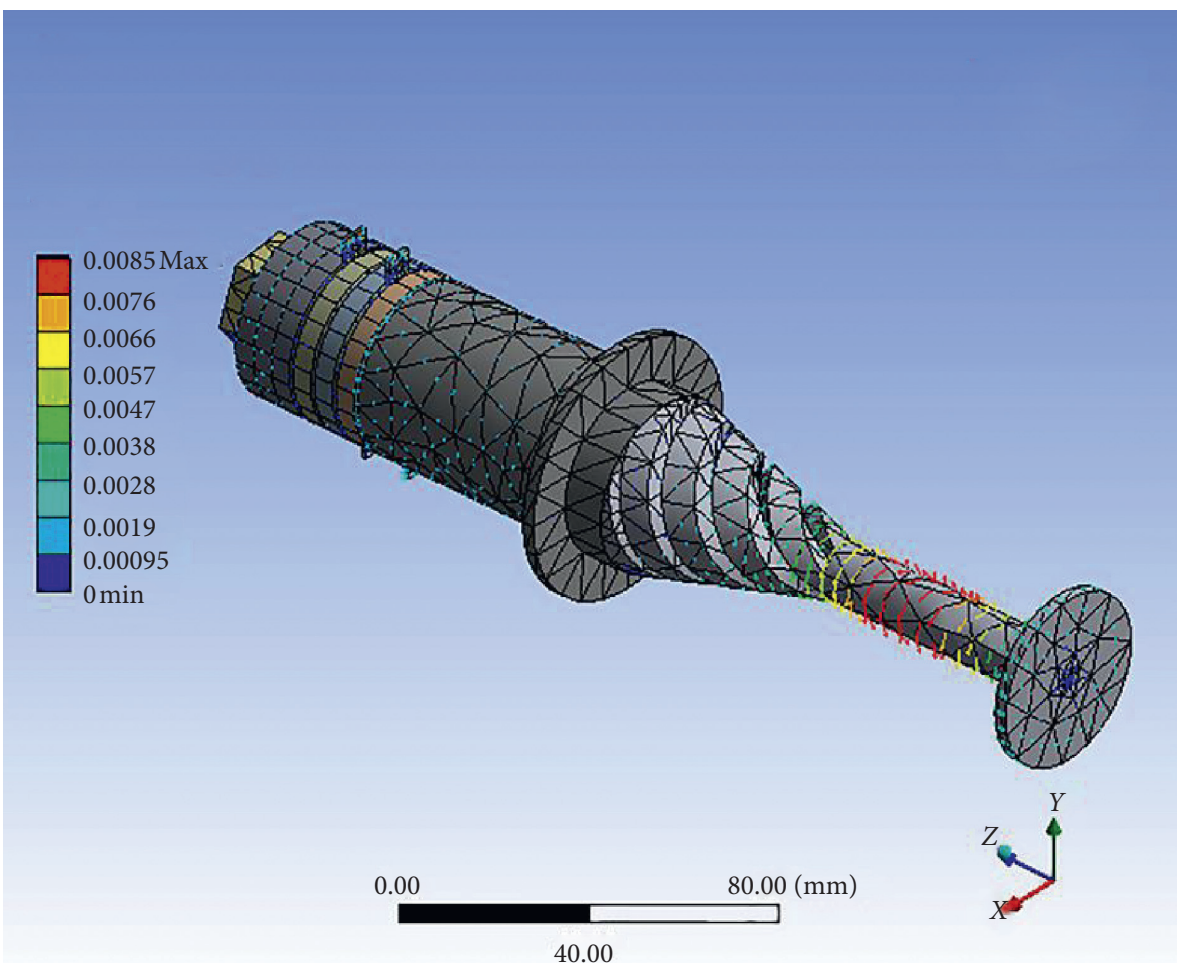

Figure 7: Modal analysis of the longitudinal-torsional compound vibration system with flange.

theoretical amplitudes of the compound horn are $19.45 \mu \mathrm{m}$, and the error is $3.3 \%$, which meets the design requirements.

\subsection{Effect of Structural Parameters of the Compound Horn on} the Frequency of the Consolidation Vibration System. Structural parameters of the compound horn include the length $L_{1}$ of the small end cylinder, the length $L_{2}$ of the big end conical part, the diameter $D_{1}$ of the small end cylinder, the inner diameter $D_{2}$ of the big end conical part, and the sector angle $\beta$ of the big end conical part, as shown in Figure 6 . Based on the parametric design function of NX, the parametric model of the compound horn was established and imported into ANSYS, and the bidirectional parameter transmission between them was established. The simulation analysis used single factor experiment method, the search frequency range was $18000-22000 \mathrm{~Hz}$, and one parameter was changed each time to analyse the effect of structural parameters on the longitudinal-torsional frequency of the consolidation vibration system.

The length $L_{1}$ of the small end cylinder of the compound horn is $54-66 \mathrm{~mm}$, and the effect on the frequency of the consolidation vibration system is shown in Figure 8. It can be seen that the frequency of the consolidation vibration 


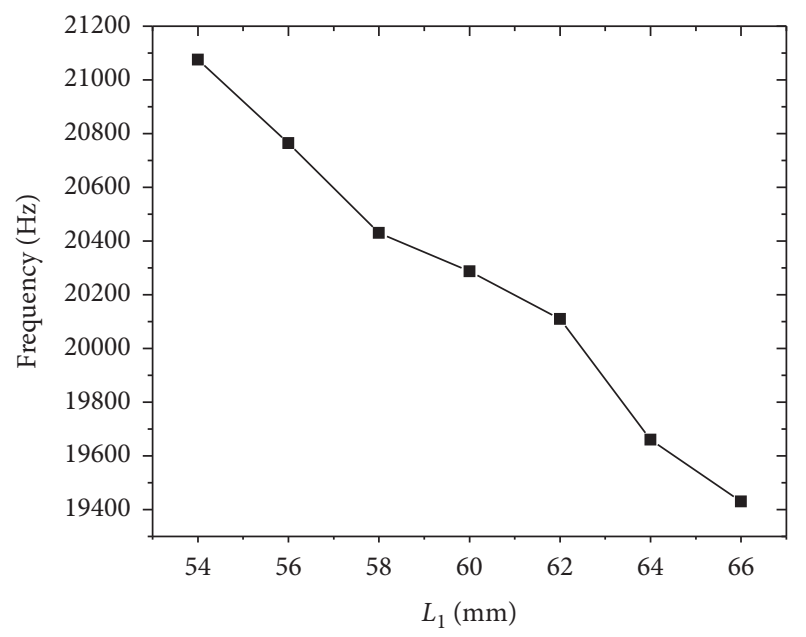

FIgURE 8: The effect of the length $L_{1}$ of the small end cylinder of the compound horn on vibration frequency.

system decreases with the increase of the length of the small end cylinder; that is to say, the length of the small end cylinder is inversely proportional to the frequency of the consolidation vibration system. When the length of the small end cylinder of the compound horn is about $63 \mathrm{~mm}$, it is close to the design frequency of $20 \mathrm{kHz}$.

The diameter $D_{1}$ of the small end cylinder of the compound horn is $9-15 \mathrm{~mm}$, and the effect on the frequency of the consolidation vibration system is shown in Figure 9. It can be seen that the frequency of the consolidation vibration system increases first and then decreases with the increase of the diameter of the small end cylinder. When the diameter of the small end cylinder of the compound horn is $13-14 \mathrm{~mm}$, it is close to the design frequency of $20 \mathrm{kHz}$.

The length $L_{2}$ of the big end conical part of the compound horn is $44-56 \mathrm{~mm}$, and the effect on the frequency of the consolidation vibration system is shown in Figure 10. It can be seen that the frequency of the consolidation vibration system decreases with the increase of the length of the big end conical part; that is, the length of the big end conical part is inversely proportional to the frequency of the consolidation vibration system. When the length of the big end conical part of the compound horn is about $53 \mathrm{~mm}$, it is close to the design frequency of $20 \mathrm{kHz}$.

The inner diameter $D_{2}$ of the big end conical part of the compound horn is $27-33 \mathrm{~mm}$, and the effect on the frequency of the consolidation vibration system is shown in Figure 11. It can be seen that the frequency of the consolidation vibration system decreases with the increase of the inner diameter of the big end conical part; that is to say, the inner diameter of the big end conical part is inversely proportional to the frequency of the consolidation vibration system. When the inner diameter of the big end conical part of the compound horn is about $31 \mathrm{~mm}$, it is close to the design frequency of $20 \mathrm{kHz}$.

The sector angle $\beta$ of the big end conical part of the compound horn is $30-60^{\circ}$, and the effect on the frequency of the consolidation vibration system is shown in Figure 12. It can be seen that the frequency of consolidation vibration

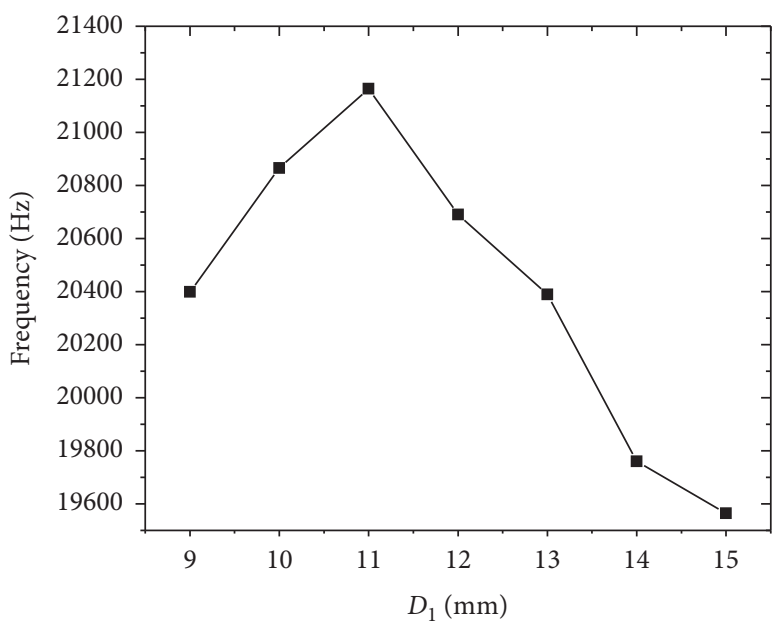

FIgURE 9: The effect of the diameter $D_{1}$ of the small end cylinder of the compound horn on vibration frequency.

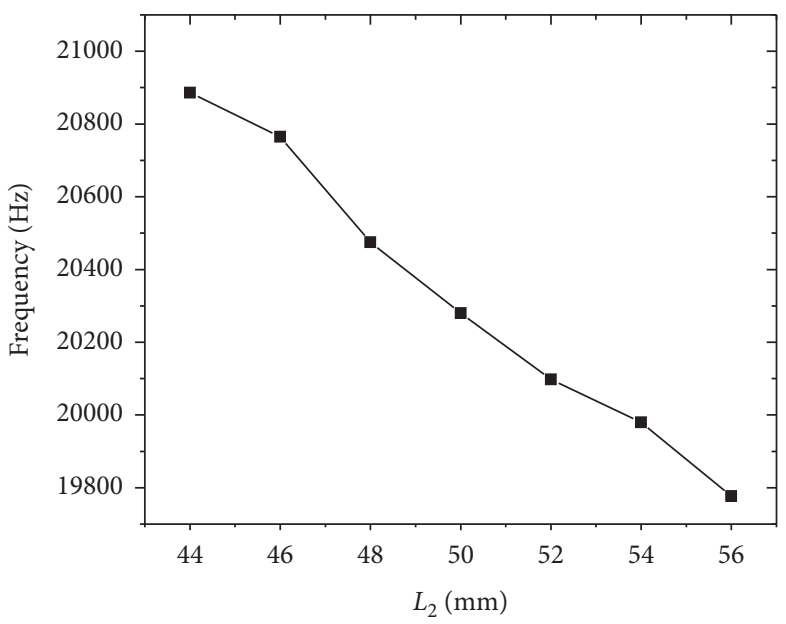

FIGURE 10: The effect of the length $L_{2}$ of the big end conical part of the compound horn on vibration frequency.

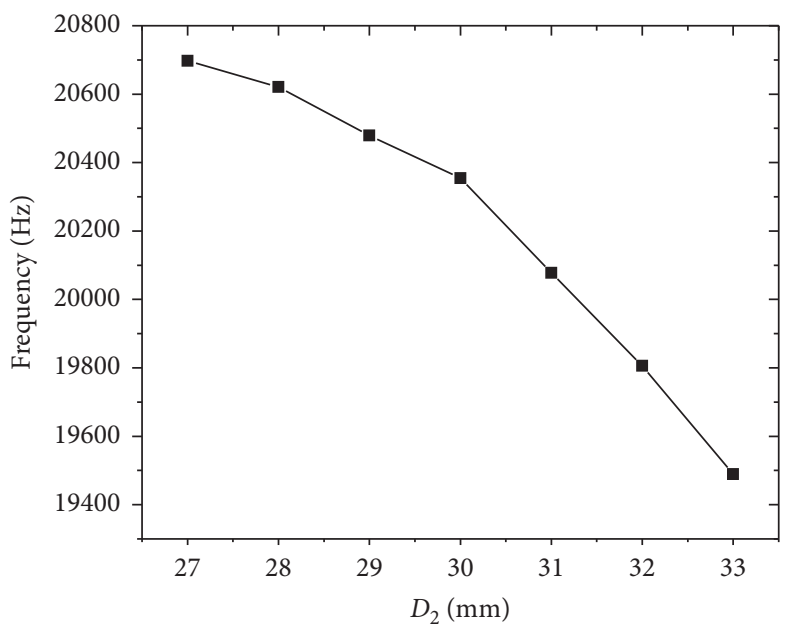

FIgURE 11: The effect of the inner diameter $D_{2}$ of the big end conical part of the compound horn on vibration frequency. 


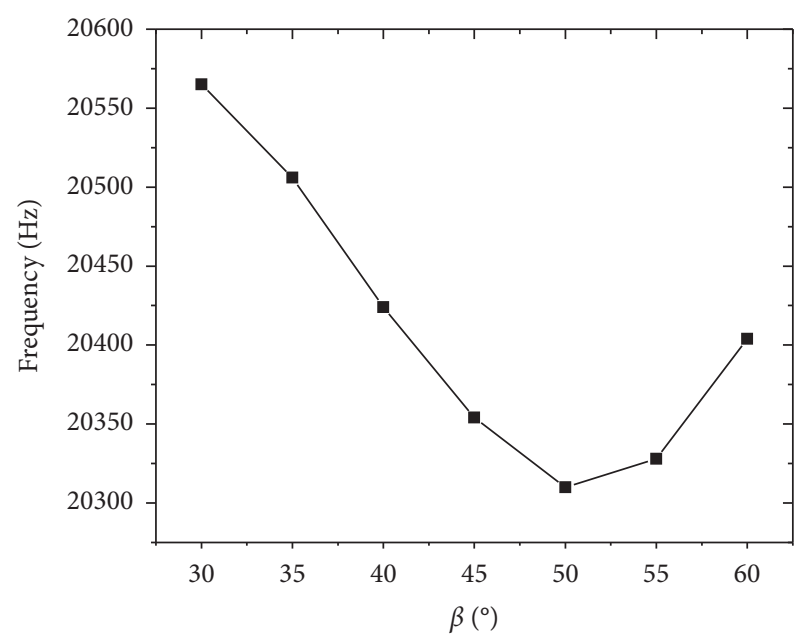

FIgURE 12: The effect of the sector angle $\beta$ of the big end conical part of the compound horn on vibration frequency.

system first decreases with the increase of the sector angle of the big end conical part, and when the sector angle is greater than $50^{\circ}$, the frequency of the consolidation vibration system increases.

Through the effect of structural parameters of the compound horn on vibration frequency, it can be seen that the change of the length $L_{1}$ of the small end cylinder, the length $L_{2}$ of the big end conical part, the diameter $D_{1}$ of the small end cylinder, the inner diameter $D_{2}$, and the sector angle $\beta$ of the big end conical part will affect vibration frequency, and the design size of the compound horn can be obtained from the analysis. Furthermore, the modal analysis can be carried out by establishing four factors and four levels orthogonal parameters to judge the effect of each parameter on the vibration frequency.

3.4. Optimization of Structural Parameters of the Compound Horn. Based on Design Exploration in ANSYS, structural parameters of the compound horn are optimized by response surface optimization. Design variables $P_{1}, P_{2}, P_{3}$, and $P_{4}$ are the diameter $D_{1}$ and the length $L_{1}$ of the small end cylinder, the inner diameter $D_{2}$, and sector angle $\beta$ of the big end conical part; the variation range of design variables is $\pm 10 \%$; and the design variable $P_{5}$ is the longitudinal-torsional frequency of the consolidation vibration system, which is the optimization objective. The mathematical model is shown in the following equation:

$$
\left\{\begin{array}{l}
f_{i}(\chi)=f\left(x_{1}+x_{2}+\cdots \cdots x_{n}\right) \\
g_{i}(\chi)=g_{i}\left(x_{1}+x_{2}+\cdots \cdots x_{n}\right)(i=1,2 \cdots \cdots n) \\
h_{i}(\chi)=h_{i}\left(x_{1}+x_{2}+\cdots \cdots x_{n}\right)(i=1,2 \cdots \cdots n)
\end{array}\right.
$$

where $\chi$ is the design variable and the value is taken according to the actual situation, $f_{i}(\chi)$ is the objective function, $g_{i}(\chi)$ is the constraint function, and $h_{i}(\chi)$ is the structural response function.

Through optimization analysis, the effects of $P_{1}, P_{2}, P_{3}$, and $P_{4}$ on the sensitivity of longitudinal-torsional frequency of the consolidation vibration system are obtained. The simulation results show that the length $L_{1}\left(P_{2}\right)$ of the small end cylinder and the inner diameter $D_{2}\left(P_{3}\right)$ of the big end conical part have an effect on the longitudinal-torsional frequency of the consolidation vibration system, which are important parameters to be considered in the optimization process.

The data in the early stage and optimization data of longitudinal-torsional frequency of the consolidation vibration system in the after stage are shown in Table 2. It can be seen that the optimization percentages of three groups of data are $1.8 \%, 1 \%$, and $2 \%$, respectively, which are less than $5 \%$ and meet the optimization requirements. Initial and correction values for design variables $P_{1}, P_{2}, P_{3}$, and $P_{4}$ are obtained.

After optimization, the amplitudes of $X, Y$, and $Z$ directions at the end of longitudinal-torsional compound consolidation vibration system are $9.55 \mu \mathrm{m}, 9.44 \mu \mathrm{m}$, and $18.9 \mu \mathrm{m}$, respectively. The amplitudes before and after optimization are shown in Table 3 . It can be seen that the optimization percentages of amplitudes in $X, Y$, and $Z$ directions are $2.6 \%, 2.4 \%$, and $0.5 \%$.

3.5. The Relationship between the Structure of Spiral Groove and the Amplitude of Torsional Vibration. The structure of spiral groove is most key factor to torsional vibration of compound horn. The displacement in modal analysis is not an absolute value. Torsional-longitudinal ratio $i$ can be used to measure the ratio between the longitudinal and torsional vibration component. Using the single factor variable analysis method, the curve of torsional-longitudinal ratio $i$ with the sector angle $\beta$ of spiral groove is shown in Figure 13; the curve of groove width $w$ and groove depth $s$ is shown in Figure 14.

It can be seen from Figure 13 that torsional-longitudinal ratio $i$ increases first, then decreases with the increase of sector angle $\beta$, and reaches the peak value at about sector angle $40^{\circ}$. It can be seen from Figure 14 that torsionallongitudinal ratio $i$ increases with the increase of groove depth $s$, when groove width $w$ increases, torsional-longitudinal ratio $i$ is basically unchanged.

\section{Experiments on the Longitudinal-Torsional Compound Piezoelectric Consolidation Vibration System for Metal Foil}

Based on theoretical calculation and optimal design, the prototype of the longitudinal-torsional compound piezoelectric consolidation vibration system for metal foil was made.

4.1. The Test Platform for Longitudinal-Torsional Compound Consolidation Vibration System. The amplitude test platform for longitudinal-torsional compound consolidation vibration system is shown in Figure 15. The test platform consists of laser vibrometer, signal generator, power amplifier, oscilloscope, and so forth. According to the principle of amplitude test, the amplitude test is carried out. 
TABLE 2: Longitudinal-torsional vibration frequency before and after optimization.

\begin{tabular}{lccr}
\hline Objective function & Before optimization & After optimization & Optimization percentage (\%) \\
\hline & & 19943 & 1.93 \\
Longitudinal-torsional vibration frequency $(\mathrm{Hz})$ & 20335 & 20087 & 1.22 \\
& & 19887 & 2.20 \\
\hline
\end{tabular}

Table 3: Amplitudes before and after optimization.

\begin{tabular}{lccc}
\hline & Before optimization $(\mu \mathrm{m})$ & After optimization $(\mu \mathrm{m})$ & Optimization percentage $(\%)$ \\
\hline$Z$ direction & 18.8 & 18.9 & 0.5 \\
$X$ direction & 9.31 & 9.55 & 2.6 \\
$Y$ direction & 9.22 & 9.44 & 2.4 \\
\hline
\end{tabular}

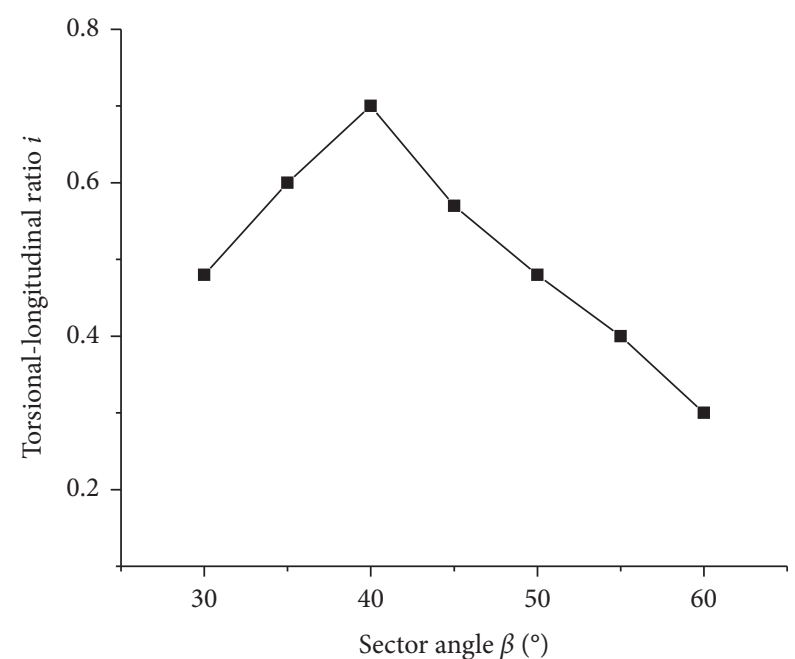

Figure 13: The effect of sector angle $\beta$ of spiral groove on torsionallongitudinal ratio $i$.

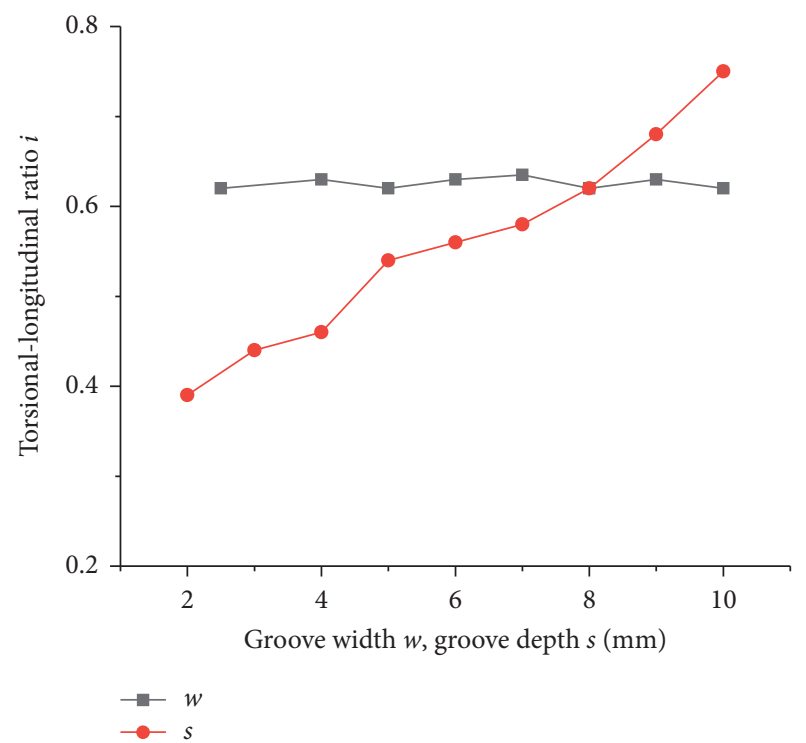

FIGURE 14: The effect of groove width $w$ and groove depth $s$ on torsional-longitudinal ratio $i$.
4.2. The Amplitude Test Analysis of Longitudinal-Torsional Compound Consolidation Vibration System. The amplitude test of longitudinal-torsional compound consolidation vibration system includes frequency-scanning and fixedfrequency experiments. The purpose of frequency-scanning is to determine the resonance frequency of the consolidation vibration system; the purpose of fixedfrequency is to determine the amplitude of the consolidation vibration system at a given resonance frequency. The three-dimensional laser vibrometer is aligned with the end face of consolidation disk, the end-face data for meshing is collected by the host computer, and the meshing point is used as the test point. The end-face normal direction $Z$ of consolidation disk is the longitudinal vibration direction, and the other two directions $X$ and $Y$ are the torsional vibration directions, which can be easily recognized by the host computer. The frequencyscanning test results are shown in Figure 16. It can be seen that the scanning range is $0-50000 \mathrm{~Hz}, X$ and $Y$ are the torsional vibrations of the consolidation vibration system, $Z$ is the longitudinal vibration. When the frequency is near $20000 \mathrm{~Hz}$, the resonance is achieved in three directions at the same time, the resonance frequency is $19800 \mathrm{~Hz}$, which is $200 \mathrm{~Hz}$ different from the design frequency of $20000 \mathrm{~Hz}$, and the error is $1 \%$ and less than $5 \%$. It meets the engineering requirements and proves that the structural design is reasonable.

When the input frequency is $19800 \mathrm{~Hz}$, the longitudinal amplitude change through the frequency-scanning test is shown in Figure 17. It can be seen that the maximum longitudinal amplitude of the system is $16 \mu \mathrm{m}$, the longitudinal amplitude after optimization is $18.9 \mu \mathrm{m}$, and the error is $2.9 \mu \mathrm{m}$. The main reasons for the errors are as follows. The theoretical calculation ignores the error and is ideal. There are some errors in the processing and assembly of the prototype. There may be some human factors during the test, which have some random errors.

When the input frequency is $19800 \mathrm{~Hz}$, the change of torsional amplitude through the frequency-scanning test is shown in Figure 18. It can be seen that maximum torsional amplitudes in $X$ and $Y$ directions of the system are $7.9 \mu \mathrm{m}$ and $8.1 \mu \mathrm{m}$, the torsional amplitudes after optimization are $9.55 \mu \mathrm{m}$ and $9.44 \mu \mathrm{m}$, and errors are $1.65 \mu \mathrm{m}$ and $1.34 \mu \mathrm{m}$. 


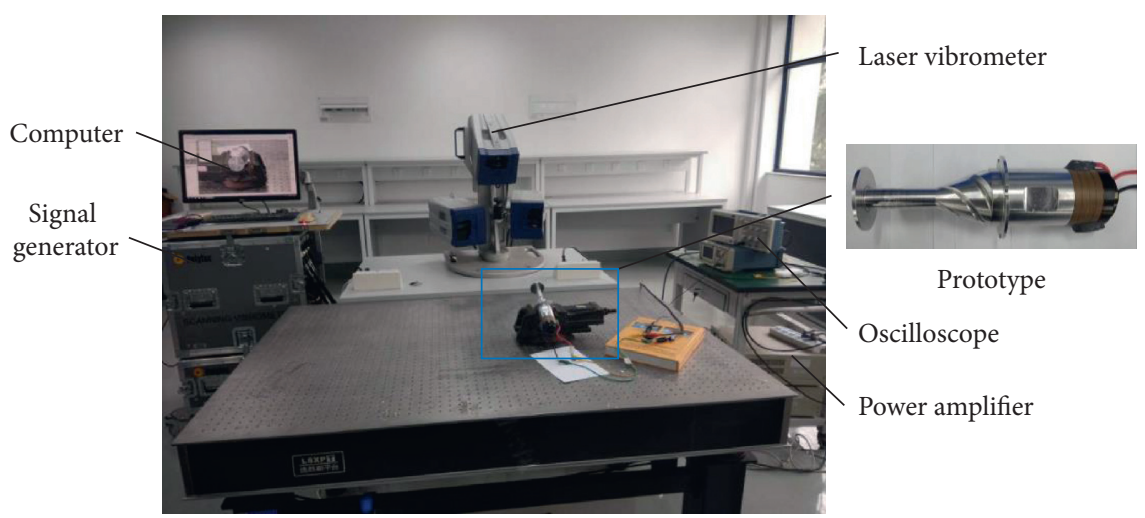

Figure 15: The amplitude experiment platform.

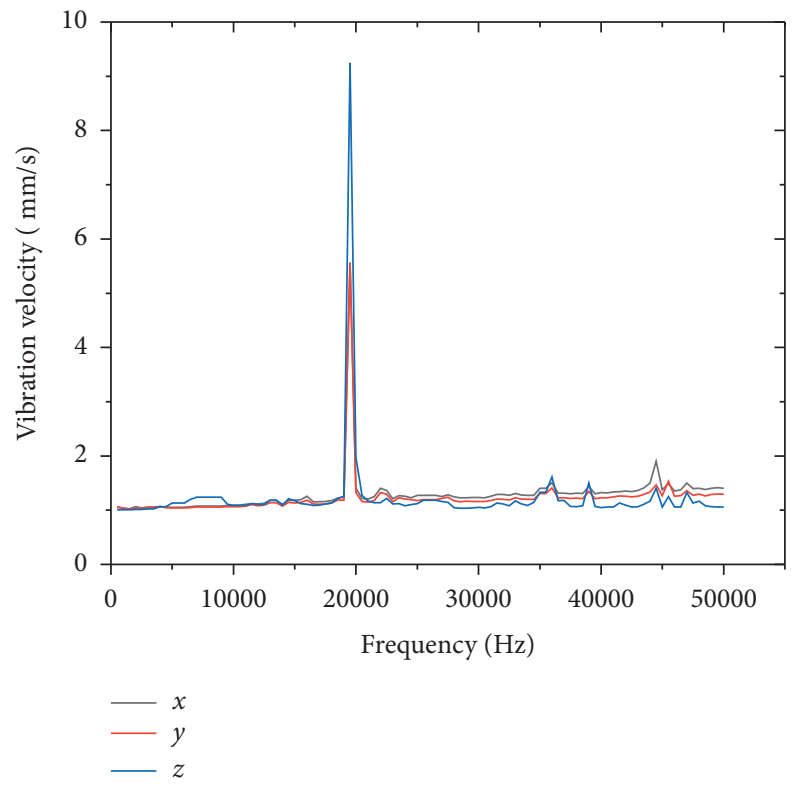

FIGURE 16: Frequency-scanning results of the consolidation vibration system.

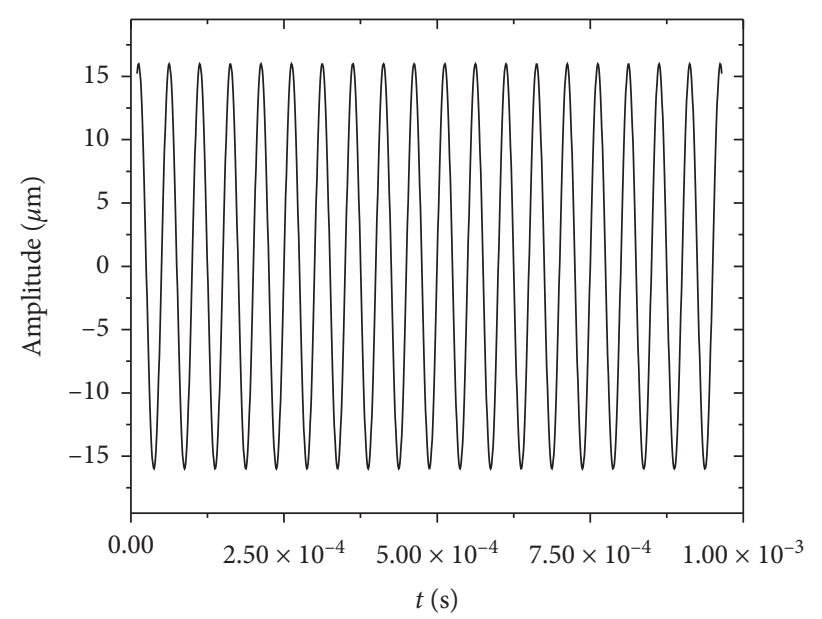

FIGURE 17: Fixed-frequency longitudinal amplitude. 


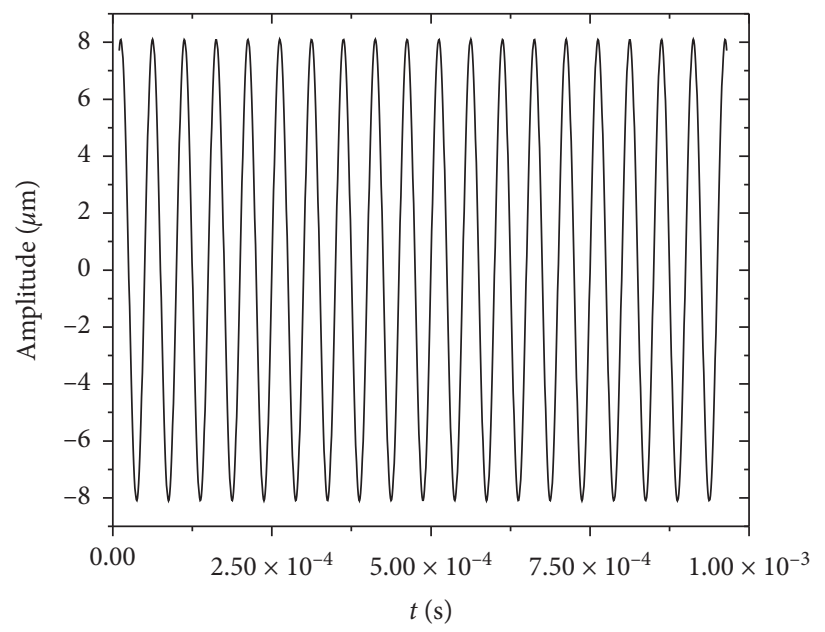

(a)

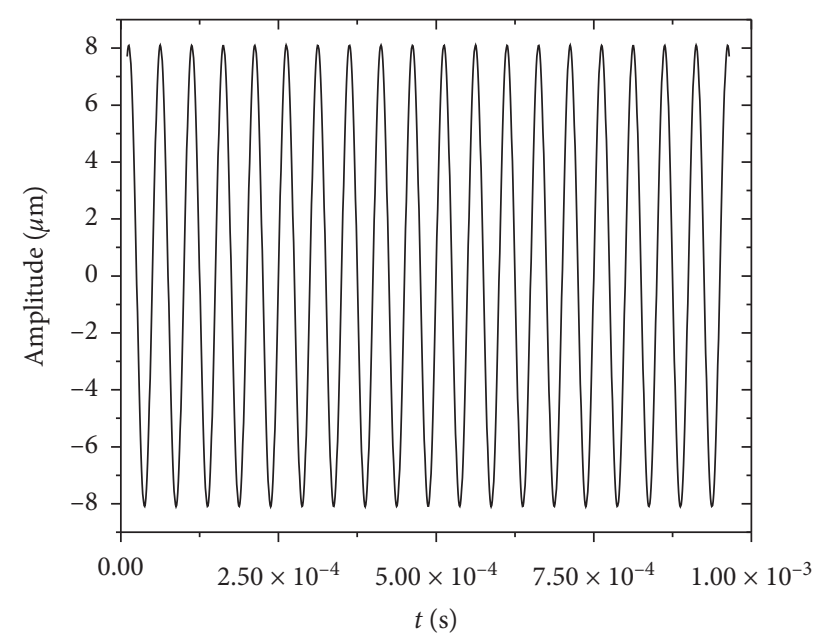

(b)

Figure 18: Fixed-frequency torsional amplitude. (a) $X$ direction and (b) $Y$ direction.

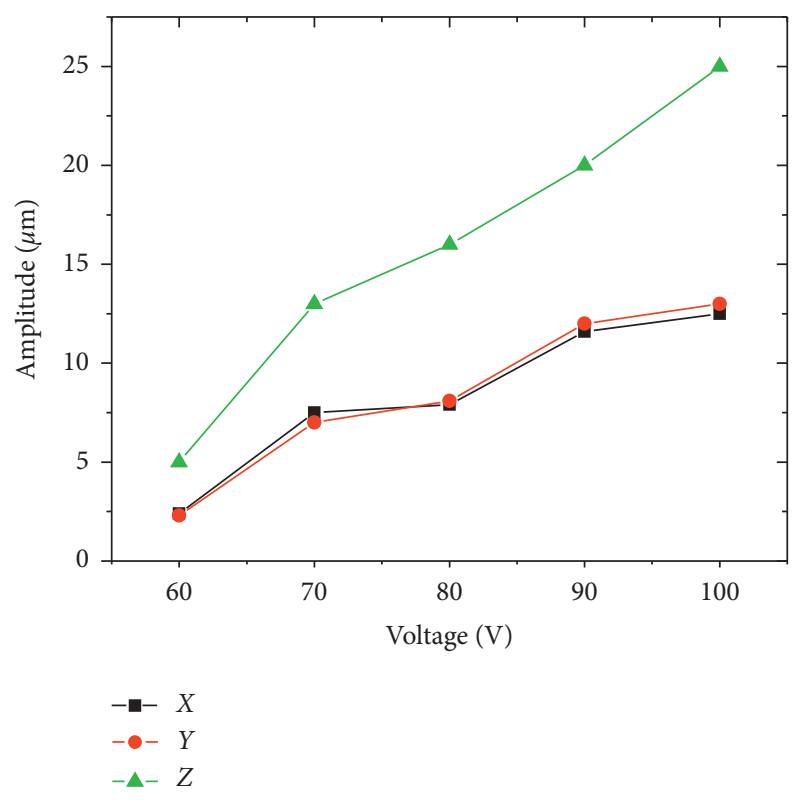

Figure 19: The relation between the output amplitude and input voltage.

4.3. The Effect of Voltage on Amplitude in the LongitudinalTorsional Compound Consolidation Vibration System. The amplitude of longitudinal-torsional compound consolidation vibration system is directly related to the input voltage; the relationship between the output amplitude of sonotrode and the input voltage is shown in Figure 19. It can be seen that when the input voltage is $60-100 \mathrm{~V}$, the output amplitude is $3-25 \mu \mathrm{m}$. The output amplitude increases gradually with the increase of the input voltage, and there is almost a linear change between them. When the input voltage is $60 \mathrm{~V}$, the output longitudinal amplitude of sonotrode is $5.2 \mu \mathrm{m}$, the torsional amplitude in the $X$ direction is $2.5 \mu \mathrm{m}$, and the torsional amplitude in the $Y$ direction is $2.6 \mu \mathrm{m}$. When the input voltage is $100 \mathrm{~V}$, the output longitudinal amplitude of sonotrode is $25.2 \mu \mathrm{m}$, the torsional amplitude in the $X$ direction is $12.6 \mu \mathrm{m}$, and the torsional amplitude in the $Y$ direction is $13.3 \mu \mathrm{m}$. The test data show that the output amplitude of sonotrode meets the consolidation requirements.

\section{Conclusion}

(1) During modal analysis, the longitudinal vibration frequency of the compound piezoelectric transducer was $19801 \mathrm{~Hz}$. The vibration frequency of the compound horn decreased with the increase in the number of spiral grooves. The vibration frequency of longitudinal-torsional compound vibration system without flange was $20576 \mathrm{~Hz}$ and the vibration frequency with flange was $20335 \mathrm{~Hz}$, which could meet the engineering requirements.

(2) During harmonic response analysis, the amplitudes of $X, Y$, and $Z$ directions at the end were $9.31 \mu \mathrm{m}$, $9.22 \mu \mathrm{m}$, and $18.8 \mu \mathrm{m}$. After optimization, the amplitudes of $X, Y$, and $Z$ directions at the end were $9.55 \mu \mathrm{m}, 9.44 \mu \mathrm{m}$, and $18.9 \mu \mathrm{m}$, respectively, which could meet the needs of engineering design.

(3) During the frequency-scanning and fixed-frequency test, the resonance frequency was $19800 \mathrm{~Hz}$, the maximum longitudinal amplitude was $16 \mu \mathrm{m}$, and the maximum torsional amplitudes in $X$ and $Y$ directions were $7.9 \mu \mathrm{m}$ and $8.1 \mu \mathrm{m}$. When the input voltage was $60-100 \mathrm{~V}$, the output amplitude of sonotrode was 3-25 $\mu \mathrm{m}$. Relevant consolidation tests for metal foil will be carried out subsequently.

\section{Data Availability}

All data generated or analysed during this study are included in this article.

\section{Conflicts of Interest}

The authors declare that they have no conflicts of interest. 


\section{Acknowledgments}

This study was supported by University Natural Science Research Project of Anhui Province (CN) (Grant no. KJ2017A121), a Project Funded by the Priority Academic Program Development of Jiangsu Higher Education Institutions, and the Postgraduate Education Innovation Foundation of Anhui Polytechnic University.

\section{References}

[1] D. White, "Ultrasonic consolidation of aluminum tooling," Advanced Materials \& Processes, vol. 161, no. 1, pp. 64-65, 2003.

[2] N. Sridharan, M. Norfolk, and S. S. Babu, "Characterization of steel-ta dissimilar metal builds made using very high power ultrasonic additive manufacturing (VHP-UAM)," Metallurgical and Materials Transactions A, vol. 47, no. 5, pp. 25172528, 2016.

[3] R. J. Friel and R. A. Harris, "Ultrasonic additive manufacturing research at Loughborough University," in Proceedings of the Twenty Third Annual International Solid Freeform Fabrication Symposium-An Additive Manufacturing Conference, Austin, TX, USA, August 2012.

[4] M. Norfolk and H. Johnson, "Solid-state additive manufacturing for heat exchangers," JOM, vol. 67, no. 3, pp. 655-659, 2015.

[5] M. Norfolk, D. Bartholomew, and C. Sidlosky, "Weld assembly for ultrasonic additive manufacturing applications," US Patent 9446475, 2016.

[6] K. Graff, C. Benedict, and J. Wenning, "Sonotrode apparatus for use in ultrasonic additive manufacturing," US Patent 9346120B1, 2016.

[7] J. Tsujino, T. Ueoka, T. Kashino, and F. Sugahara, "Transverse and torsional complex vibration systems for ultrasonic seam welding of metal plates," Ultrasonics, vol. 38, no. 1-8, pp. $67-71,2000$.

[8] J. Tsujino, "Ultrasonic motor using a one-dimensional longitudinal-torsional vibration converter with diagonal slits," Smart Materials and Structures, vol. 7, no. 3, pp. 345-351, 1998.

[9] J. Tsujino, T. Ueoka, K. Otoda, and A. Fujimi, "One-dimensional longitudinal-torsional vibration converter with multiple diagonally slitted parts," Ultrasonics, vol. 38 , no. 1-8, pp. 72-76, 2000.

[10] J. Tsujino, Y. Harada, S. Ihara, K. Kasahara, M. Shimizu, and T. Ueoka, "Configurations of high-frequency ultrasonics complex vibration systems for packaging in microelectronics," Ultrasonics, vol. 42, no. 1-9, pp. 125-129, 2004.

[11] T. Asami and H. Miura, "Longitudinal-torsional vibration source consisting of two transducers with different vibration modes," Japanese Journal of Applied Physics, Article ID 07KE08, vol. 55, pp. 1-5, 2016.

[12] H. Al-Budairi and M. Lucas, "An analytical model of a longitudinal-torsional ultrasonic transducer," Journal of Physics Conference Series, vol. 382, Article ID 012061, 2012.

[13] H. Al-Budairi, M. Lucas, and P. Harkness, "A design approach for longitudinal-torsional ultrasonic transducers," Sensors and Actuators A: Physical, vol. 198, pp. 99-106, 2013.

[14] Q. Zhang, S. Shi, and W. Chen, "An electromechanical coupling model of a longitudinal vibration type piezoelectric ultrasonic transducer," Ceramics International, vol. 41, no. Supplement 1, pp. S638-S644, 2015.
[15] X. Lu, J. Hu, H. Peng, and Y. Wang, "A new topological structure for the Langevin-type ultrasonic transducer," $U l$ trasonics, vol. 75, pp. 1-8, 2017.

[16] K. Nakamura, M. Kurosawa, and S. Ueha, "Characteristics of a hybrid transducer-type ultrasonic motor," IEEE Transactions on Ultrasonics, Ferroelectrics and Frequency Control, vol. 38, no. 3, pp. 188-193, 1991.

[17] B. X. Zhang, "Research on longitudinal-torsional system of metal foil consolidation based on ultrasonic vibration," Master Thesis, Anhui Polytechnic University, Wuhu, China, 2019.

[18] L. Ma, "Study on structure and vibrational characteristics of longitudinal-torsional composite ultrasonic machining device," Master Thesis, Henan Polytechnic University, Jiaozuo, China, 2014.

[19] T. Chen, S. L. Liu, W. Liu, and C. Q. Wu, "Study on a longitudinal-torsional ultrasonic vibration system with diagonal slits," Advanced Mechanical Engineering, vol. 9, no. 7, pp. 1-10, 2017.

[20] K. Nakamura, M. Kurosawa, and S. Ueha, "Design of a hybrid transducer type ultrasonic motor," IEEE Transactions on Ultrasonics, Ferroelectrics and Frequency Control, vol. 40, no. 4, pp. 395-401, 1993.

[21] S. Ueha, H. Nagashima, and M. Masuda, "Longitudinaltorsional composite transducer and its applications," Japanese Journal of Applied Physics, vol. 26, no. S2, pp. 188-190, 1993.

[22] S. Y. Lin, "Sandwiched piezoelectric ultrasonic transducers of longitudinal-torsional compound vibrational modes," IEEE Transactions on Ultrasonics Ferroelectrics \& Frequency Control, vol. 44, no. 6, pp. 1189-1197, 1993.

[23] B. Zhao, W. B. Bie, X. B. Wang, F. Chen, and B. Q. Chang, "Design and experimental investigation on longitudinaltorsional composite horn considering the incident angle of ultrasonic wave," International Journal of Advanced Manufacturing Technology, vol. 105, no. 1-4, pp. 325-341, 2019.

[24] S. Yin, B. Zhao, and Y. Li, "Design of a mode conversion type longitudinal-torsional composite ultrasonic vibration machining system," Journal of Vibration and Shock, vol. 38, no. 11, pp. 242-248, 2019. 